\title{
Evaluation and Grading of Students' Writing: Holistic and Analytic Scoring Rubrics
}

\author{
Abeer Al-Ghazo \\ Associate Professor \\ Department of English Language and Literature, Ajloun National University, Jordan \\ Issam Ta'amneh \\ Associate Professor \\ English Language \& Translation Department, Isra University, Jordan
}

Received: September 11, 2021 Accepted: September 30, $2021 \quad$ Published: October 2, 2021

doi:10.5296/jsel.v9i1.19060ＵRL: https://doi.org/10.5296/jsel.v9i1.19060

\begin{abstract}
The paper tries to investigate the most preferable writing scoring rubrics when assessing students' writing assignments and to find the dimensions that teachers who teach English as a foreign language (EFL) emphasize when scoring EFL writing summaries. Thirty male and female Jordanian EFL teachers who teach English in both basic and secondary schools were participated to collect the necessary data. To conduct the study, a questionnaire consisting of twenty-seven items was prepared and disturbed by the researchers to suit the purpose of the study. In order to analyze the participants' respondents in the questionnaire, the researchers calculate Percentages, Means, Standard Deviations. The results revealed that there is a high interest in using analytic scoring rubrics to correct their students' writing. The total mean reached 3.27 with standard deviation (0.65) by high agreement degree. Moreover, the results also highlight the importance of using scoring rubrics as precise and effective methods to assess the learners' writing performance.
\end{abstract}

Keywords: Rubrics, Holistic Scoring, Analytic Scoring, Writing Competence, Evaluation 


\section{Introduction}

The goal of any educational policy is to prepare learners to become proficient in English language. Consequently, to achieve this goal, students should master the main language skills which involve listening, speaking, reading and writing (Chawwang, 2008). Writing seems the most productive difficult skill (MacIntyre \& Gardner, 1989; Kurk\&Atay, 2007; Latif, 2007) because writing production depends on grasp of vocabulary, grammar, logical sequence of ideas and presentation of mechanical prosperities such as capitalization spelling, paragraphing, punctuation, references, and appearance.

Learners also need to learn how to arrange ideas, select suitable words; form sentences and then combine these sentences into coherent paragraphs. For this reason, we cannot deny that EFL learners suffer from weaknesses in writing despite the efforts of educationalists to correct this weakness.

Whiteman (1985) states that students are not good at writing because teachers do not involve them in the writing tasks as teachers emphasize on teaching grammar, vocabulary, capitalization and spelling. Beside teachers neglect a proper evaluation of their students' pieces of written work. The evaluation of writing, in a process-oriented classroom, is a crucial issue to a writing development and students' learning improvement. One of the main purposes of writing evaluation is to provide corrections and give correct feedback.

Harvard Study of Writing (cited in Klim 2011) points out clearly that the feedback that is presented to the students by their teachers is so important as it provides the students with the needed evidences to show them their ability or disability of performing or failing in doing a writing task. This action is necessary as it helps the students in their choices of favorite majors.

A rubric is considered an excellent way for evaluating and assessing the learners' writing tasks (Schafer, 2004). It is a well-organized criterion that is used to arrange a scale for the students' expected writing tasks and the scores that they deserve for the presented writing tasks. (Campbell, Melenyzer, Nettles, \& Wyman, 2000).A rubric is used to assess the overall proficiency level of a given written work on the scale. These descriptors are essential to give reliable, valid discrimination and good evaluation. Herman, Aschbacher, and Winters (1992) point out that there are many characteristic features of a rubric scale. First, it has a well-organized list of criteria for the raters and the test-takers. Second, it has standards for the different levels of writing proficiency and performance. Third, it has gradations of written quality. Fourth, it contains modal exemplars of expected performance level.

Weigle (2002) mentions that there are three types of rubrics that are used when assessing the students' written tasks. These are primary trait, analytic and holistic scoring rubrics. Kuo (2007) indicates that these three types differ in their degree of bias, their impact, inter-rater reliability, the cost-effectiveness, and discriminatory power. Many studies have used analytic rubrics, holistic rubrics, and other studies have compared both types of those scoring rubrics. 
Perkins (1983) outlines the consequences and procedures of using three principles methods of writing that include holistic, analytic and trait evaluation. In trait scoring, teachers assign holistically based on a certain feature of the writing that is being emphasized such as the structure of student's piece of writing, the vocabulary or the tone. In this type, teachers need to know the extent to which the writing piece exhibits the certain traits that are essential to accomplishing a writing purpose. In the holistic evaluation, one or more readers evaluate the text as a whole and a single grade is assigned to it based on an overall impression. Holistic scoring criteria consist of some general guidelines that define good writing performance at each score point. These criteria involved "The clarity with which the thesis is stated, developed and supported, the effectiveness with which an issue has been raised, treated and resolved, the sufficiency of the support and development of the thesis for the reader, the degree to which the writer has accommodate the needs of the intended audience, the degree of grammatical and lexical cohesion and overall coherence of the piece, and The effectiveness use of rhetorical devices. (Perkins 1983)

Weigle (2002) concludes that the holistic rubrics are considered effective and practical as they short and they can be done quickly. They do not include much detailed criteria of assessment and evaluation so they serve the interests of university departments and employers.

In contrast, when using the analytical rubrics, the written tasks are divided into separate parts to be graded and evaluated fairly. In this method, learners can be provided with precise diagnostic feedback. An analytic scoring rubrics typically include writing components relating to the written content, organization, vocabulary, language and mechanics. This type of rubric offers more detailed information about a learners' writing proficiency than do the single score of a holistic scoring rubric. In this method, teachers can get comprehensive feedback about the weak or strong aspects in their learners' written work (Hamp-Lyons, 1995; and Crehan, 1997). In choosing an evaluative tool, EFL teachers need to know and weigh the disadvantages and advantages of each to decide the best procedures that is objective, fair and efficient.

Jacobs et al. (1981) indicates that ESL analytic schema is considered as the bestknown analytical scoring scale. Hamp-Lyons (1990, 78) commented that it is "the best-known scoring procedure for ESL writing at the present time". This rubric is divided into five components: content, organization, vocabulary, language, and mechanics with each one having four rating levels of excellent to very good, good to average, fair to poor, and very poor.

Writing skills are arranged into different ranges as in the following: first, content 13-16 (very poor), 17-21, (fair to poor), 22-26 (good to average) and 27-30 (excellent. Second, organization 7-9 (very poor), 13-10, (fair to poor), 17-14 (good to average) and $18-20$ (excellent to very good). Third, vocabulary 7-9 (very poor), 
10-13, (fair to poor), 14-17 (good to average) and 18-20 (excellent). Fourth, language 5-10 (very poor), 11-17, (fair to poor), 18-21 (good to average) and 22-25 (excellent) and the last component is mechanics 2 (very poor), 3 (fair to poor), 4 (good to average) and 5 (excellent). (Jacobs et al., 1981). Any researcher has to follow these ESL composition profile, and then expresses the rating of learner's written work in percentages. Each level and component has its own descriptor that has a specific level and a special numerical scale.

Brown (1991) using a sample of some essays provided the scores that they deserve after evaluating them using the rubric scale that is consisted of three categories content organization, discourse syntax, vocabulary and mechanics. Many researchers did not agree to the system of weighting that is used for each category. At every level of proficiency, written practice provides diagnostic feedback that help our learners improve their linguistic proficiency and accuracy. A key to successful assessment and evaluation is to get your learners to understand that their grades are just forms of feedback to identify their writing performance and then create input for the next piece of writing. Weir (1990) indicates that evaluating any EFL essays has been mainly for diagnostic and developmental purposes.

In order to help our learners to identify their writing competence, holistic and analytic scoring tools are used in different EFL and ESL programs levels for different purposes. Some of these techniques may be a combination of analytical and holistic rubrics as the Jacobs' et al. (1981). The main question is: Which scoring rubric, holistic or analytic, is more preferred by teachers to evaluate their students' writing proficiency?

Many studies tried to study and compare the teachers' behaviors toward holistic and analytic scoring rubrics. Chi (2001) uses many-faceted Rasch measurement to find the most appropriate scoring rubrics. The results revealed that there are significant differences between raters using holistic scoring rubrics, but not analytic scoring rubrics. Jacobs et al., (1981), Perkins, (1983), Al-Fallay, (2000); Knoch, (2009); Nakamura, (2004) confirmed that analytic rubric is chosen for diagnostic purposes because teachers and learners can get comprehensive feedback about their performance. By contrast, Wiseman, (2012) indicates that holistic scoring rubrics offer many advantages of reduced cost in money and time.

Several studies are investigating the importance of using scoring rubrics for written assessment. Bacha (2001) conducts a study to find out which scoring rubrics can provide EFL teachers about their learner' essay writing competence. The researcher used ESL Composition Profile by Holly Jacobs et al., 1981.The researcher carried out the study on a sample final exam essay written by L1 Arabic non-native students of English at the Lebanese American University. The findings revealed analytical scoring rubrics are more beneficial to provide comprehensive feedback about learners writing performance.

Shi (2001) examines differences in rater judgment of Forty-six teachers (23 Chinese 
and 23 English teachers) who evaluated ten essays by using a 10 -point scale. The scale has these categories: content, organization, language, and length. Findings revealed that there are not any significant differences between non-native English speakers and native English speakers in their scores for the 10 essays.

Yin (2010) explores teachers' perceptions when conducting a classroom language assessment in an EAP context in a British university. In this study, two teachers observed their learners during teaching activities as an assessment form. Those teachers observed the classroom pedagogy across one semester. After each observation, the teachers were asked to recall their thoughts during classroom assessment practices as they were revealed to them in video excerpts selected by the researcher. The results revealed that the two teachers shared a number of common assessment practices such as reading students' written scripts and observations of their group discussions.

Zhang and Elder (2011) conduct an empirical study to evaluate the oral English proficiency of 10 English speakers' speech samples who are elicited by CET-SET of China.19 native English and 20 non-native English teachers provide data which were derived from holistic scoring rubrics. After analyzing the data quantitatively and qualitatively, the results revealed that there were not any significant differences in raters' holistic judgments of the speech samples

Hijikata-Someya et al (2015) examine the ratings of EFL summaries written by 51 Japanese students who study at university. In order to identify differences in EFL instructors' evaluations, three native English speakers and three non-native English speakers used the Educational Testing Service's holistic rubric. The results reveal that there is a lower Cronbach's alpha coefficient for NNES raters when compared to NES raters.

Thikra, K.et al (2015) use analytic and holistic scoring rubrics to compare EFL learners' scores on essay writing performance. The participants of the study were 30 Yemeni students attending an English undergraduate program. The researchers used suitable statistical analysis to attain the correct results. The results reveal that both Holistic Analytic rubrics are reliable and valid tools to evaluate learners' writing competence.

Qasim and Qasim (2015) examine Pakistani university teachers' perspectives and their viewpoints toward the effectiveness of using rubrics to evaluate their students' writing performance. Through extensive interviews with six respondents indicated the perceived advantages and disadvantages of use of these kinds of rubrics. The results also revealed that the teachers give a crucial importance to details and elaborations.

Hosseini and Mowlaie (2016) investigate the possible significant effect of using the analytic and the holistic assessments on improving Iranian EFL learners' writing skill. To achieve the purpose of study, the EFL participants were divided into two 
groups. The participants writing compositions in Group (A's) were scored holistically while the students' writing compositions in group B's were scored analytically. The results reveal that both scoring methods caused statistically significant differences between pre- and post-test in both groups.

Yamanishi, Ono and Hijikata (2019) examine the applicability of analytic and holistic scoring rubric to classrooms in the EFL context. 16 summaries written by Japanese EFL university student writers were evaluated by six teachers using the new rubric developed by the Educational Testing Service (ETS). After analyzing the results quantitatively and qualitatively, the results revealed that The results reveal that the overall quality dimension could work well even if used alone, and the new rubric and the ETS holistic rubric had a positive and moderate correlation for L2 summary writing evaluation .

Ono, Yamanishi, and Hijakata (2019) try to reveal teachers' perceptions of grading the writing task on the TOEFL IBT. To achieve the reliability and validity, teacherraters' holistic and analytic ratings are investigated. Seven raters used both a holistic and an analytic scale to score 36 compositions and completed a questionnaire about their perceptions of the scales. Results revealed that both holistic and analytic scoring rubrics exhibited high inter-rater reliability and there were high correlations between them.

\section{Purpose of the Study}

In order to enhance students' writing competence, they need to know their level of proficiency and this can be achieved through the assessment and evaluation of their writing summaries. This study tries to investigate the most preferable writing scoring rubrics when assessing students' writing assignments and to find the dimensions that EFL teachers emphasize when scoring EFL writing summaries

The study tries to answer the following questions:

1- Which scoring rubric, holistic or analytic, is more preferred by EFL teachers to evaluate their students' writing proficiency?

2- Which dimensions do EFL teachers emphasize when scoring EFL writing summaries?

3- Do these kinds of rubric give a clear picture about the students' writing competence?

\section{Statement of the Problem}

Writing seems to be the most difficult skill because any writing production depends on many factors such as grammar rules, grasp of vocabulary, logical sequence of ideas (coherence and cohesion of the ideas) and presentation of mechanical prosperities such as spelling, punctuation, citation of references, appearance. There are many reasons behind the EFL learners' weakness in writing, one of these reasons is because teachers in different educational stages focus on some of language 
components such as grammar and vocabulary rather than trying to concentrate and develop their students' writing competencies. Beside they neglect a proper evaluation and assessment of their learners' written work. The evaluation and assessment are very crucial to improve and develop student's writing. Due to the challenging nature of writing in foreign language, EFL teachers have to find appropriate teaching and assessment methods to improve their learners' proficiency in writing skill.

\section{Significance of the Study}

This study aims at identifying the most important and appropriate teaching and assessment methods and rubrics that can be used for writing assessment to enhance and improve the learners' proficiency in writing skill. It also gives EFL teachers an opportunity to diagnose their students' weaknesses and strengths in their writing competence through using the proper evaluation and assessment methods. Moreover, scoring rubric also gives the learners with more correct detailed information about their writing performance. In addition, using suitable and correct rubrics can be helpful for program developers in which that these kinds of using rubrics can play an essential role in remedial courses to focus and concentrate on the weak points and to determine the degree of mastery of a given writing task

\section{Method and Procedures}

In this section, the researchers present the methodology which includes the participants of the study, the instrument, validity and reliability of the instrument, and the appropriate statistical analysis.

\subsection{Participants}

To conduct the study, thirty male and female Jordanian EFL teachers in both basic and secondary schools participated in the study. They have had a good experience in teaching English.

\subsection{The Instrument}

In order to investigate the most preferable evaluation rubrics that EFL teachers use in evaluating their students' writing, the researchers prepared a questionnaire. The questionnaire consisting of 27 items based on Likert Four-Point Scale. The researchers used a four-point Likert Scale: (4) reflected strongly agree (SA), (3) reflected agree (A), (2) reflected disagree (D) and (1) reflected strongly disagree (SD).

\subsubsection{Validity and Reliability of the Instrument}

To achieve the validity of the questionnaire, the researchers asked a jury of EFL specialists in various Jordanian universities to assess the questionnaire. All their suggestions were taken into account when adopting the final draft of the questionnaire. As for the reliability of the questionnaire, Cronbch's alpha coefficient was calculated. It was found to be (0.84). This value is considered satisfactory and reliable to adapt the questionnaires in order to collect the needed data. 


\subsubsection{The Questionnaire Correcting Method}

To find the degree of acceptance, the researcher used the following model (Oxford, 2003) that classified the means into three levels according to their categories.

\section{Results and Discussion}

The study tries to investigate the most preferable evaluation rubrics that EFL teachers use in evaluating their students' writing. Moreover, it tries to find the dimensions that EFL teachers emphasize when scoring EFL writing summaries, and whether these kinds of rubric give the teachers a clear picture about their students writing competence.

The first question was: Which scoring rubric, holistic or analytic, is more preferred by EFL teachers to evaluate their students' writing proficiency?

To answer this question, the researchers measured the means and standard deviations for teachers' responses in the questionnaire's items.

Table (2): Means and Standard Deviation for Teachers' Perspectives toward the Effect of Holistic Scoring on Improving the Writing Skill

\begin{tabular}{|c|l|c|c|c|}
\hline No & Items & Mean & $\begin{array}{l}\text { Standard. } \\
\text { Deviation }\end{array}$ & $\begin{array}{l}\text { Agreement } \\
\text { Degree }\end{array}$ \\
\hline $\mathbf{1}$ & $\begin{array}{l}\text { I think holistic scoring rubrics assess the } \\
\text { learners' writing proficiency level. }\end{array}$ & 1.85 & 0.80 & Low \\
\hline $\mathbf{2}$ & $\begin{array}{l}\text { I think holistic scoring rubrics have the } \\
\text { highest construct validity. }\end{array}$ & 2.03 & 0.73 & Low \\
\hline $\mathbf{3}$ & $\begin{array}{l}\text { I think holistic scoring rubrics are done } \\
\text { quickly and impressionistically }\end{array}$ & 2.13 & 0.94 & Low \\
\hline $\mathbf{4}$ & $\begin{array}{l}\text { I think holistic scoring rubrics are more } \\
\text { practical ones. }\end{array}$ & 2.35 & 0.86 & Medium \\
\hline $\mathbf{5}$ & $\begin{array}{l}\text { I prefer using holistic scoring rubrics } \\
\text { because they can not be subjective. }\end{array}$ & 1.85 & 0.74 & Low \\
\hline $\mathbf{6}$ & $\begin{array}{l}\text { I see that it is difficult to obtain reliable } \\
\text { scoring through using holistic scoring } \\
\text { rubrics. }\end{array}$ & 1.83 & 0.81 & Low \\
\hline $\mathbf{7}$ & $\begin{array}{l}\text { I think holistic scoring rubrics have many } \\
\text { advantages e.g., they reduce cost in time } \\
\text { and money. }\end{array}$ & 1.95 & 0.75 & Low \\
\hline $\mathbf{8}$ & $\begin{array}{l}\text { I prefer using holistic scoring rubrics } \\
\text { because they help me in assessing and } \\
\text { evaluating the students' }\end{array}$ & 1.93 & 0.76 & $\mathbf{1 0 w}$ Total Means whole. \\
\hline
\end{tabular}

Table (2) shows that means ranging from (1.83-2.35). Item 4 "I think holistic scoring rubrics are more practical ones." receives the highest mean (2.35) with 
standard deviation (0.86) while the lowest mean was (1.83) with standard deviation (0.81) for item (6) "I see that it is difficult to obtain reliable scoring through using holistic scoring rubrics". The total mean reached 1.99 with standard deviation (0.071) by low agreement.

Table (3): Means and Standard Deviation for Teachers' Perspectives toward the Effect of Analytic Scoring on Improving the Writing Skill

\begin{tabular}{|c|c|c|c|c|}
\hline No & Items & Mean & $\begin{array}{l}\text { Standard. } \\
\text { Deviation }\end{array}$ & $\begin{array}{l}\text { Agreement } \\
\text { Degree }\end{array}$ \\
\hline $\mathbf{1}$ & $\begin{array}{l}\text { I think that analytic scoring rubrics are more } \\
\text { precise diagnostic feedback that can be } \\
\text { presented for the students. }\end{array}$ & 3.66 & 0.48 & High \\
\hline 2 & $\begin{array}{l}\text { I think that analytic scoring rubrics are better } \\
\text { because they assess the features of a given } \\
\text { written sample separately. }\end{array}$ & 3.200 & 0.414 & High \\
\hline 3 & $\begin{array}{l}\text { I think that analytic scoring rubrics provide } \\
\text { my students with comprehensive feedback. }\end{array}$ & 3.46 & 0.516 & High \\
\hline 4 & $\begin{array}{l}\text { I think that analytic scoring rubrics put much } \\
\text { emphasis on various dimensions of students' } \\
\text { written work. }\end{array}$ & 2.86 & 0.83 & Medium \\
\hline 5 & $\begin{array}{l}\text { I think that analytic scoring rubrics have more } \\
\text { ability to discriminate the weak as well as the } \\
\text { strong aspects of the students' writing } \\
\text { performance. }\end{array}$ & 3.80 & 0.414 & High \\
\hline 6 & $\begin{array}{l}\text { I think that that analytic scoring rubrics are } \\
\text { not preferred scoring method especially in } \\
\text { long-scale testing context. }\end{array}$ & 2.88 & .680 & Medium \\
\hline \multicolumn{2}{|c|}{ Total Means } & 3.31 & 0.166 & High \\
\hline
\end{tabular}

Table (3) shows that the means ranging from (2.86-3.80). It also shows that item (5) " I think that analytic scoring rubrics have higher discriminating power of the weak and strong sides in learners' writing competence." receives the highest mean (3.80) with standard deviation (0.414), followed by item 1 " I think that analytic scoring rubrics are more precise diagnostic feedback that can be presented for the students." with mean (3.66) with standard deviation (0.48). The lowest means was (2.86) with standard deviation (.83) for item (4)"I think that analytic scoring rubrics put much emphasis on various dimensions of students' written work. "The total mean reached (3.31) with standard deviation $(0.166)$ by high agreement degree.

After analyzing the results of the items taken by teachers, one can observe that there is a high interest in using analytic scoring rubrics to correct their students' writing. Teachers think that analytic scoring rubrics are more precise diagnostic feedback that can be presented to the students. They also assess the features of a given written sample so they have higher discriminating power of the weak and strong 
sides in learners' writing competence. This indicates that the majority of EFL teachers who hold the responsibilities of teaching writing in secondary schools preferred using an analytic scoring rubric that provide them with comprehensive feedback about their students' writing performance.

Although some of the teachers shows that holistic scoring rubrics reduce cost in time and money and they are more practical because they are short and do not include detailed criteria, and the body of work is assessed as a whole, they are in favor of analytic scoring rubrics. This method of scoring allows for more diagnostics in which students can know their weakness in writing then try to improve and enhance it .(Bacha, 2001;Cumming, 1997; Hamp-Lyons, 1995) assert that holistic rubrics cannot provide EFL learners or teachers with a sufficient feedback that may improve the learners' writing performance.

Question Two: Which dimensions do EFL teachers emphasize when scoring EFL writing summaries?

To answer this question, the researchers measured the means and standard deviations for teachers' responses in the questionnaire items.

Table (4): Means and Standard Deviation for Dimensions that EFL Teachers Focus on When Scoring Writing Summaries

\begin{tabular}{|l|l|c|c|c|}
\hline No & Items & Mean & $\begin{array}{l}\text { Standard } \\
\text { Deviation }\end{array}$ & $\begin{array}{l}\text { Agreement } \\
\text { Degree }\end{array}$ \\
\hline $\mathbf{1}$ & $\begin{array}{l}\text { I put much emphasis on how well the } \\
\text { passage's content was significant, } \\
\text { appropriate and well thought out. } \\
\text { (Content). }\end{array}$ & 3.75 & 1.55 & High \\
\hline $\mathbf{2}$ & $\begin{array}{l}\text { I put much emphasis on how well the } \\
\text { written sample was organized. } \\
\text { (Organization). }\end{array}$ & 3.15 & 1.27 & Medium \\
\hline $\mathbf{3}$ & $\begin{array}{l}\text { I put much emphasis on word choice and } \\
\text { the appropriate use expressions. } \\
\text { (Vocabulary). }\end{array}$ & 3.20 & 1.24 & Medium \\
\hline $\mathbf{4}$ & $\begin{array}{l}\text { I put much emphasis on sentential and } \\
\text { discourse grammar. (Languag). }\end{array}$ & 3.70 & 1.22 & High \\
\hline $\mathbf{5}$ & $\begin{array}{l}\text { I put much emphasis on writing rules. } \\
\text { (Mechanics) }\end{array}$ & 3.05 & 1.23 & Medium \\
\hline $\mathbf{6}$ & $\begin{array}{l}\text { I put much emphasis on the clarity that } \\
\text { the thesis is stated and supported. } \\
\text { (Clarity of thesis). }\end{array}$ & 3.25 & 1.33 & $\mathbf{3 . 3 5}$ \\
\hline Total Means
\end{tabular}

As shown in Table 4, two out of six dimensions that EFL teachers focused on when scoring writing summaries are at the level of high. These dimensions are content 
(3.75) and language (3.70). Through assessment writing summaries, teachers put much emphasis on their student's comprehension of the topic they have written about, whether they write the statement first and the outlines of the essay before they start writing or not, and whether they have been able to write more narroweddown statements and support them through using more supporting sentences or not. Moreover, teachers try to focus on meaningful and logical sequence of the sentences and the correct use of the words through assessing any written samples (sentential and discourse grammar).

The results also show that there is a medium awareness of how well the written sample was organized. They consider that students still have some problems indirect quotations, complex and compound sentences, adverb and adjective clauses, using punctuations ... etc.

Question three: Do these kinds of rubric give a clear picture about their students writing competence?

Table 5: Percentages, Means, Standard Deviations and Rank of the Effects of Rubrics on Writing Competence

\begin{tabular}{|c|c|c|c|c|c|c|c|c|c|}
\hline \multirow{2}{*}{ Ran $k$} & \multirow{2}{*}{$\begin{array}{l}\text { Dimension } \\
\text { ID }\end{array}$} & \multirow{2}{*}{ Items } & \multicolumn{5}{|c|}{ Percentages in Categories: } & \multirow{2}{*}{ Mean } & \multirow{2}{*}{$\begin{array}{l}\text { Std. } \\
\text { Dev. }\end{array}$} \\
\hline & & & S.D. & D. & Neutral & A. & S.A. & & \\
\hline 1 & 1 & $\begin{array}{l}\text { Using holistic and analytic scoring rubrics } \\
\text { are highly helpful and effective for essay } \\
\text { scoring. }\end{array}$ & 0.0 & 0.0 & 15.0 & 75.0 & 10.0 & 3.875 & 0.40 \\
\hline 2 & 2 & $\begin{array}{l}\text { Using holistic and analytic scoring rubrics } \\
\text { provide a sufficient feedback that may } \\
\text { improve the learners' accuracy and fluency } \\
\text { in their writing.. }\end{array}$ & 0.0 & 0.0 & 50.0 & 50.0 & 0.0 & 3.490 & 0.62 \\
\hline 3 & 3 & $\begin{array}{l}\text { Using holistic and analytic scoring rubrics } \\
\text { can enable teachers to diagnose their } \\
\text { students' weak points. }\end{array}$ & 0.0 & 20.0 & 55.0 & 25.0 & 0.0 & 3.067 & 0.51 \\
\hline 4 & 4 & $\begin{array}{l}\text { By using scoring rubrics, students will be } \\
\text { more confident in teachers' comments. }\end{array}$ & 0.0 & 10.0 & 85.0 & 5.0 & 0.0 & 2.900 & 0.35 \\
\hline 5 & 5 & $\begin{array}{l}\text { Using holistic and analytic scoring rubrics } \\
\text { can not provide learners with a clear } \\
\text { picture of their weak points. }\end{array}$ & 0.0 & 40.0 & 45.0 & 15.0 & 0.0 & 2.767 & 0.69 \\
\hline 6 & 6 & $\begin{array}{l}\text { Using holistic and analytic scoring rubrics } \\
\text { draw learners' attention to their spelling, } \\
\text { grammar, and punctuation. }\end{array}$ & 0.0 & 0.0 & 50.0 & 0.0 & 50.0 & 2.325 & 0.49 \\
\hline 7 & 7 & $\begin{array}{l}\text { Using holistic and analytic scoring rubrics } \\
\text { try to overcome my students' shortcomings } \\
\text { through meaningful feedback. }\end{array}$ & 0.0 & 0.0 & 40.0 & 60.0 & 0.0 & 2.290 & 0.47 \\
\hline \multicolumn{3}{|c|}{ Over Whole } & 0.0 & 5.0 & 85.0 & 10.0 & 0.0 & 3.050 & 0.31 \\
\hline
\end{tabular}




\section{MInstitute ${ }^{\text {Mank }}$}

Table 5 shows that the overall degree for the effects of rubrics on writing competence is moderate as the mean is 3.050. The table also shows that item (1)"Using holistic and analytic scoring rubrics are highly helpful and effective for essay scoring." receives the highest mean (3.87) with standard deviation (0.40). This is followed by item (2) "Using holistic and analytic scoring rubrics provide a sufficient feedback that may improve the learners' accuracy and fluency in their writing" with mean (3.06) with standard deviation (0.62). The lowest means was (2.29) with standard deviation (.47) for item (7)"Using holistic and analytic scoring rubrics try to overcome my students' shortcomings through meaningful feedback".

This result highlights the importance of using holistic and analytic rubrics as precise and effective methods to assess the learners' writing performance. It shows that using holistic and analytic scoring rubrics provide a sufficient feedback that may improve the learners' accuracy and fluency in their writing. It shows that using these kinds of scoring rubrics would enable teachers to diagnose their students' weak points. Learners' attention would be drawn to their spelling, grammar, punctuation, capitalization, and handwriting errors. The findings agree with (Bitchener, Young, \& Cameron, 2005), and (Liu, 2008) who have shown that sufficient feedback on learner's errors either grammatical or lexical ones results in significant improvement in their writing competence and performance. The results are in complete harmony with the result of Hosseini, Mowlaie (2016) who have shown that there is a significant effect of analytic and holistic assessments on improving writing skill among Iranian EFL learners.

\section{Conclusion}

Holistic and analytic rubrics are scoring scales used by EFL teachers as a process of evaluating the students' writing compositions. There are many benefits for using scoring rubrics as a tool to assess students' writing performance. They can provide sufficient feedback that may improve the learners' accuracy and fluency in their writing task and to overcome the grammatical and lexical errors. In other words, students can overcome their shortcomings through meaningful feedback. The results reveal using analytical rubrics yields is more accurate and consistent than using holistic scoring methods. Teachers consider that analytic scoring rubrics are more precise diagnostic feedback that can be presented for their learners because they can assess the features of a given written sample so they have higher discriminating power of the weak and strong aspects in writing performance as well as the learning needs. To sum up, without providing feedback in writing, students will not be able to improve and monitor their progress effectively and efficiently.

\section{References}

Al-Fallay, I. (2000). Examining the analytic marking method: Developing and using an analytic scoring schema. Language \& Translation, 12, 1-22.

Bacha, N. (2001). Writing evaluation: what can analytic versus holistic essay 
scoring tell us? System, 29(3), 371-383.

Bitchener, J., Young, S., \& Cameron, D. (2005).The effect of different types of corrective feedback on ESL student writing. Journal of second language writing, 14(3), 191-205.

Brown, J. D. (1991). Do English and ESL faculties rate writing samples differently? TESOL Quarterly, 25, 587-603.

Campbell, D. M., Melenyzer, B. J., Nettles, D. H., \& Wyman, R. M. Jr. (2000). Portfolio and performance assessment in teacher education. Boston: Allyn and Bacon.

Chawwang, N. (2008). "An Investigating of English Reading Problems of Thai 12th Grade Students in Nakhonratchasima Educational Region 1, 2, 3 and 7", Master Thesis, Srinakharinwirot University, Bangkok, Thailand.

Chi, E. (2001). Comparing holistic and analytic scoring for performance assessment with many-facet Rasch model. Journal of Applied Measurement, 2(4), 379-388.

Crehan, K. (1997, October). A discussion of analytic scoring for writing performance assessments. Paper presented at the Arizona Education Research Association, Phoenix, AZ.

Cumming, A. (1990). Expertise in evaluating second language compositions. Language Testing, 7(1), 31-51.

Hamp-Lyons, L. (1995). Rating nonnative writing: The trouble with holistic scoring. TESOL Quarterly, 29, 759-762.

Hamp-Lyons, L. (1990). Second language writing: Assessment issues. In B. Kroll (Ed.), Second language.

Harvard Study of Writing, Online available from https://www.unl.edu/writing/assessing-student-writing

Herman, J. L., Aschbacher, P. R., \& Winters, L. (1992). A practical guide to alternative assessment. Alexandria, VA: Association for Supervision and Curriculum Development.

Hijikata, Y., Yamanishi, H., \& Ono, M. (2011, June). The evaluation of L2 summary writing: Reliability of aholistic rubric. Paper presented at the Tenth Symposium on Second Language Writing. Taipei, Taiwan: Howard International House.

Hosseini, M., \& Mowlaie, B. (2016). Effect of Holistic vs. Analytic Assessment on Improving Iranian Intermediate EFL Learners' Writing Skill. Journal of Language and Translation, 6(11), 31-41.

Jacobs, H. L., Zingraf, S. A., Wormuth, D. R., Hartfiel, V. F., \& Hughey, J. B. (1981). Testing ESL composition: A practical approach. Rowley, MA: Newbury 


\section{MInstitute Macho $^{\text {Mnink }}$}

House writing: Research insights for the classroom (pp. 69-87). New York: Cambridge University Press.

Knoch, U. (2009). Diagnostic assessment of writing: A comparison of two rating scales. Language Testing, 26(2), 275-304.

Kurk, G., \& Atay, D. (2007). Students' Writing Apprehension. Journal of Theory and Practice in Education, 3(1), 12-23.

Latif, M. A. (2007). The factors accounting for the Egyptian EFL university students' negative writing affect. Essex Graduate Student Papers in Language \& Linguistics., 9, 57-82. Retrieved from: http://www.essex.ac.uk/linguistics/publications/egspll/volume_9/pdf/57-82\%20Muhammad.p df

MacIntyre, P. D., \& Gardner, R. C. (1989). Anxiety and Second Language Learning: Toward a theoretical clarification. Language Learning, 39(2), 251-275.

Nakamura, Y. (2004). A comparison of holistic and analytic scoring methods in the assessment of writing. Retrieved from https://jalt.org/pansig/2004/HTML/Nakamura.htm

ONO, YAMANISHI, and HIJIKATA (2019) .Holistic and Analytic Assessments of the TOEFL $i B T \AA$ Integrated Writing Task. Japan Language Testing Association. vol. 22: pp. 65-88, 2019.

Perkins, K. (1983). On the use of composition scoring techniques, objective measure, and objective tests to evaluate ESL writing ability. TESOL Quarterly, 17(4), 651-67.

Qasim A. Qasim, Z. (2015). Using Rubrics to Assess Writing: Pros and Cons in Pakistani Teachers' Opinions. Journal of Literature, Languages and Linguistics. https://www.iiste.org/Journals/index.php/JLLL/article/view/27152/0

Schafer, L. (2004). Rubric. Retrieved February 9, 2015, from http://www.etc.edu.cn/eet/articles/rubrics/index.htm

Shi, L. (2001). Native- and nonnative-speaking EFL teachers' evaluation of Chinese students' English writing. Language Testing, 18, 303-325. http://dx.doi.org/10.1177/026553220101800303

Thikra K. Ghalib, T \& Al-Hattami, A. (2015). Holistic versus Analytic Evaluation of EFL Writing: A Case Study. English Language Teaching; 8(7), 225-235.

Weigle, S. C. (2002). Assessing Writing. Cambridge: Cambridge University Press. Kuo, S. (2007). Which rubric is more suitable for NSS liberal studies? Analytic or holistic? Educational Research Journal, 22(2), 179-199.

Weir, C. J. (1990). Communicative language testing. Englewood Cliffs, NJ: Prentice Hall Regents. 


\section{Mll Macrothink}

Wiseman, S. (2012). A Comparison of the Performance of Analytic vs. Holistic Scoring Rubrics to Assess L2 Writing. Iranian Journal of Language Testing, 2(1), 59-92.

White, E. M. (1985). Teaching and assessing writing. San Francisco, CA: JosseyBass.

Yamanishi, H., Ono, M., \& Hijikata, Y. (2019). Developing a scoring rubric for L2 summary writing: a hybrid approach combining analytic and holistic assessment. Lang Test Asia, 9, 13. https://doi.org/10.1186/s40468-019-0087-6

Yin, M. (2010). Understanding Classroom Language Assessment through Teacher Thinking Research. Language Assessment Quarterly, 7(2), 176-195.

Zhang, Y., \& Elder, C. (2011). Judgments of oral proficiency by non-native and native English speaking teacher raters: Competing or complementary constructs? Language Testing, 28, 31-50. http://dx.doi.org/10.1177/0265532209360671

\section{Appendix 1}

\begin{tabular}{|c|c|c|c|c|c|}
\hline No. & Statements & $\begin{array}{l}\text { Totally } \\
\text { Agree }\end{array}$ & Agree & Disagree & $\begin{array}{l}\text { Totally } \\
\text { Disagree }\end{array}$ \\
\hline & \multicolumn{5}{|c|}{ Evaluation and Grading of Students' Writing : (Holistic and Analytic Scoring) } \\
\hline $1-$ & $\begin{array}{l}\text { I think holistic scoring rubrics assess the learners' writing } \\
\text { proficiency level. }\end{array}$ & & & & \\
\hline $2-$ & $\begin{array}{l}\text { I think holistic scoring rubrics have the highest construct } \\
\text { validity. }\end{array}$ & & & & \\
\hline $3-$ & $\begin{array}{l}\text { I think holistic scoring rubrics are done quickly and } \\
\text { impressionistically }\end{array}$ & & & & \\
\hline 4- & I think holistic scoring rubrics are more practical ones . & & & & \\
\hline $5-$ & $\begin{array}{l}\text { I prefer using holistic scoring rubrics because they can't be } \\
\text { subjective. }\end{array}$ & & & & \\
\hline $6-$ & $\begin{array}{l}\text { I see that it is difficult to obtain reliable scoring through } \\
\text { using holistic scoring rubrics. }\end{array}$ & & & & \\
\hline 7- & $\begin{array}{l}\text { I think holistic scoring rubrics have many advantages e.g. } \\
\text { they reduce cost in time and money. }\end{array}$ & & & & \\
\hline $8-$ & $\begin{array}{l}\text { I prefer using holistic scoring rubrics because they help me } \\
\text { in assessing and evaluating the students' works as a whole. }\end{array}$ & & & & \\
\hline 9- & $\begin{array}{l}\text { I think that analytic scoring rubrics are more precise } \\
\text { diagnostic feedback that can be presented for the students. }\end{array}$ & & & & \\
\hline $10-$ & $\begin{array}{l}\text { I think that analytic scoring rubrics are better because they } \\
\text { assess the features of a given written sample separately. }\end{array}$ & & & & \\
\hline $11-$ & I think that analytic scoring rubrics provide my students & & & & \\
\hline
\end{tabular}




\section{Macrothink}

Journal for the Study of English Linguistics

ISSN 2329-7034

2021, Vol. 9, No. 1

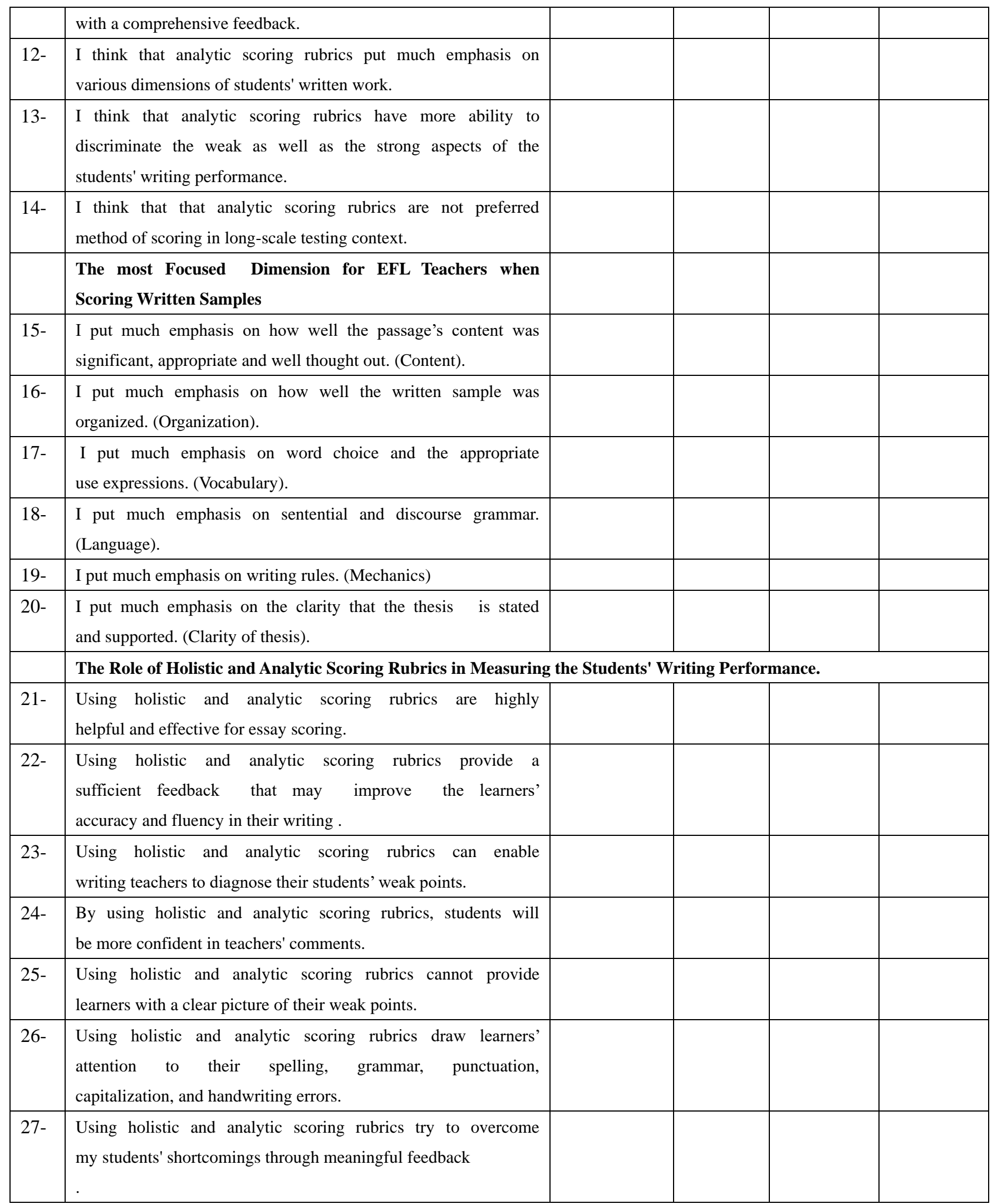




\section{Copyright Disclaimer}

Copyright for this article is retained by the author(s), with first publication rights granted to the journal.

This is an open-access article distributed under the terms and conditions of the Creative Commons Attribution license (http://creativecommons.org/licenses/by/4.0/). 